\title{
I'm Doing the Best I Can (for Myself): Leadership and Variance of Harvesting in Resource Dilemmas
}

\author{
Jeroen Stouten and David De Cremer \\ Tilburg University
}

\author{
Eric van Dijk \\ Leiden University
}

\begin{abstract}
Previous research on social dilemmas has shown that leadership can be an effective means to supervise a common resource and that group members prefer a leader when confronted with high variance between group members' harvests. In this article, the authors investigate how leaders and followers react to variance. The results of an experimental study indicate that leaders are especially likely to harvest more than followers (and to deviate from the optimal harvest) when there is high variance between group members' harvests. Moreover, this role effect was explained, at least partly, by the fact that compared with followers, leaders felt more entitled to higher harvests. The findings suggest that assigning leadership may, under certain situations, lead to inefficiency in managing the common resource.
\end{abstract}

Keywords: leadership, resource dilemma, entitlement

Hardin (1968) described in his article "The Tragedy of the Commons" a situation in which herdsmen share a common pasture in which their cattle are allowed to eat the fresh grass. Each herdsman tries to keep as many cattle as possible on the commons in order to maximize his own profits. However, when one herdsman decides to add more cattle to the pasture, the collective shares the consequences, because fewer resources are then available for the other herdsmen. Yet consequences will be severe only when other herdsmen also add more cattle to the commons, which results in the overgrazing of the pasture and no grass left for the cattle of any herdsman. Hence, a defecting choice, such as adding more cattle to the pasture, will always result in a higher payoff than cooperation, but if all act in this way, all will be worse

Jeroen Stouten and David De Cremer, Department of Economic and Social Psychology, Tilburg University, Tilburg, the Netherlands; Eric van Dijk, Department of Social and Organizational Psychology, Leiden University, Leiden, the Netherlands.

This research was supported by Grant 016.005 .019 from the Netherlands Organization for Scientific Research awarded to David De Cremer.

Correspondence concerning this article should be addressed to Jeroen Stouten, Department of Economic and Social Psychology, Tilberg University, P.O. Box 90153, 5000 LE Tilburg, the Netherlands. E-mail: jeroen.stouten@ uvt.nl off than if they cooperate (Dawes, 1980). These particular situations are known as social dilemmas and, more specifically, resource dilemmas (Komorita \& Parks, 1994).

In social dilemmas, the installment of a leader is a preferred solution to enhance cooperation and to supervise the use of the common resource pool. However, to date, little empirical research is known to have addressed the behavior that leaders posit in these kinds of situations. Prior resource dilemma research has demonstrated that leaders are believed to constitute an efficient and fair way to maintain resources (Messick et al., 1983; Rutte \& Wilke, 1984). In fact, group leaders are expected to act in a responsible and just manner serving the group's interests (Samuelson \& Messick, 1995). However, more recent research has shown that leaders may actually take more from the resource than followers do (De Cremer, 2003; De Cremer \& van Dijk, 2005; Samuelson \& Allison, 1994). For example, De Cremer (2003) argued that this role effect was due to the fact that leaders felt more entitled to receive larger shares from the resource. This entitlement explanation relates closely to different research approaches. For example, social cognition research suggests that the position one has in a group activates certain role schemas, which hold interrelated cognitions, such as thoughts, beliefs, and attitudes (Fiske \& Taylor, 1991). 
On one hand, the leader role schema holds that a leader should act in a responsible manner, but on the other hand, it comprises the belief that a leader should receive certain privileges and entitlements (Messick et al., 1983; Samuelson \& Allison, 1994). Moreover, equity theory (Adams, 1965), which states that people's outcomes should be in relation to their inputs, also emphasizes the role of entitlement. Because leaders generally must make important decisions and are considered to be more influential, their inputs are expected to be higher than followers' inputs. Leaders thus find themselves entitled to receive a higher payoff than followers and actively pursue this goal.

But is this always true? Will leaders always put their own interests first? In our opinion, people are more likely to behaviorally adhere to their given roles when there is an ambiguous harvesting norm, that is, when the resource situation at hand fails to dictate clear expectations and social norms. Indeed, if group members harvest in a clear and consistent manner, a strong situation emerges in which it is clear how normative one's behavior should be. However, if the situation is weak and norms are not clear because people's harvests are highly variable, people will rely more on their own beliefs and feelings of entitlement. Hence, leaders' harvests relative to followers' harvests will be influenced by the expected differences in feelings of entitlement only when the situation is more ambiguous and not when a clear harvesting norm exists.

It is interesting to note that prior social dilemma research has exactly shown that under circumstances in which there is high variance between group members' harvests (Samuelson \& Messick, 1986; Samuelson, Messick, Rutte, $\&$ Wilke, 1984), people prefer to install leaders. Indeed, resource dilemma research has demonstrated that the greater the variance in group members' harvests is, the more people will increase their harvests. The resulting inefficient use of the common resource may then require a structural change. However, when group members keep their harvests close to a norm, such as the highest harvest one can take in order to maintain the resource pool from depleting, conformity pressures will be strong, and harvests will remain close to this norm (see, e.g., Messick et al., 1983; Samuelson, 1993; Samuelson \& Messick, 1986; Samuelson et al., 1984).

The purpose of the present study was to investigate how leaders versus followers think and act when confronted with high- versus lowvariability harvesting groups. To summarize our hypotheses, first, we expected that leaders would recognize their influence to the group (see equity theory) and would reason that they have a greater impact on the group decisions than followers do. Second, we expected leaders to indicate that they are entitled to harvest more than followers. Third, we expected leaders to harvest more than followers when the variance in group harvests is high. No such difference was expected when variance is low. Finally, this role effect under circumstances of high variance was expected to be mediated by feelings of entitlement (see De Cremer, 2003, for a similar line of reasoning).

\section{Method}

\section{Participants and Design}

Ninety-two undergraduate students participated voluntarily in exchange for 7 euro (approximately U.S. \$6). All participants were randomly allocated to the experimental conditions of the role manipulations and variance manipulations.

\section{Procedure}

Upon entering the laboratory, participants were welcomed by the experimenter and then placed in separate cubicles containing a chair, a table, and a computer. Further instructions were presented on the computer screen. Participants were led to believe that they would be interacting via the computer, which was connected to a general server (in reality, participants were not able to interact and communicate with each other).

Participants were told that they were part of a 6-person group that would play several trials of a game. ${ }^{1}$ Group members were referred as Group Members 1 to 6 (in reality, all participants learned that they were Group Member 2). Further, participants learned that they would be playing a fixed number of trials and that in each trial they could take a certain amount of points

\footnotetext{
${ }^{1}$ For some sessions, fewer than 6 people arrived to participate. Regardless of how many individuals actually arrived for each session, however, participants were led to believe that 6 participants had arrived. This procedural detail is consistent with that used by others (see Kerr \& Kaufman-Gililand, 1994).
} 
from a common resource pool. Participants were told that the initial pool size was set to 1,500 points. In each trial, participants would be able to simultaneously harvest a certain amount of points from the resource pool. However, participants learned, each group member could harvest up to 50 points. At the end of each trial, the points that were left in the resource pool would be multiplied by a replenishment factor, 1.1, so that the pool size was constrained to a maximum of 1,500 points (see, e.g., Samuelson \& Messick, 1986; Samuelson et al., 1984). Participants were told that they could continue to harvest points from the resource pool as long as the pool contained more than zero points or until the experimenter stopped the experiment. Hence, if each group member were to take an amount of points equal to the optimal harvest, 22.72 points (hence 23 points, because participants were only able to take whole points), the initial pool size could be kept stable.

If group members were to harvest in a responsible manner from the resource pool, they could harvest for a long time. For group members this would be particularly interesting, because each point harvested would increase personal income and was worth 0.05 euro (U.S. $\$ 0.04)$. The total of harvested points would be paid after the experiment. After this introduction, participants were questioned regarding their understanding of the game. All participants answered these questions successfully.

Appointing a leader. Participants were told that in groups where decisions must be made there is often a leader and that, hence, in this situation a leader would be appointed. To appoint a leader in a legitimate manner, the person who scored highest on a questionnaire assessing leadership qualities would be appointed leader of the group. Participants filled out the selfdeveloped 26-item Management Assessment Inventory, consisting of such items as "Leadership is a matter of influencing others" and "A leader should be able to command respect." After a short interval, participants received bogus feedback about the results of the inventory. Participants in the leadership condition learned that in the remainder of the experiment, Group Member 2 (i.e., the participant) would perform the leader role in the group. Participants in the follower condition learned that Group Member 5 would be the leader and that they would be followers. Then participants were asked a few questions concerning their role in the group.
Manipulation of variance. Participants next started playing the resource dilemma game. In two trials, group members could withdraw a number of points from the resource pool. After the first trial, participants were told, group members' individual withdrawals would be shown, and hence, each group member would be able to see how much each other member had harvested. In reality, however, after the first trial, group members' individual harvests were manipulated. Half of the participants learned that the harvests of the other five group members were low in variance. The other half learned that the other group members had harvested in a high-variance behavioral pattern. Harvests after the first trial were manipulated in such a way that the mean would be equal to the optimal harvest and equal across experimental conditions. However, in line with Samuelson et al. (1984), the standard deviations between the low and high conditions were different. The standard deviation (based on the other five group members' harvests) in the low-variance condition was 3 points. In the high-variance condition the standard deviation was 14 points. After the first trial, participants saw the following harvests from the other group members in the low-variance condition: 19, 21, 24, 24, 27. In the high-variance condition participants saw the following harvest sizes: $6,14,23,31,41$. Hence, participants in the low-variance condition saw that the other group members' harvests were close to the optimal harvest, whereas those in the high-variance condition saw that group members' harvests were highly divergent and that participants were unequally harvesting from the common resource pool.

Dependent measures. All questions were answered on a 7-point scale (ranging from $1=$ not at all to $7=$ very much so). First, to check for the manipulation of variance, participants were asked to what extent there was high variance in the harvesting behavior in the group; to check for the manipulation of role, participants were asked whether they had been assigned the role of leader or follower in the group (dichotomously scored).

Then, to assess feelings of entitlement, participants were asked, "To what extent do you think you have the right to earn more than the 
others?"2 Further, participants were asked how much impact they thought they had on the group. Finally, participants' harvests were measured in a first trial (before harvest feedback was given) and a second trial (after feedback was given).

\section{Results}

\section{Manipulation Checks}

A 2 (role) $\times 2$ (variance) analysis of variance (ANOVA) on the variance manipulation check item revealed only a main effect for variance, $F(1,88)=58.77, p<.001, \eta^{2}=.40$. Participants in the high-variance condition thought there was more variance in harvesting behavior $(M=4.83, S D=1.61)$ than participants in the low-variance condition $(M=2.52, S D=1.24)$. For the role manipulation (leader vs. follower) question, 91 of 92 participants (99\%) answered correctly. Hence, our manipulations were successful.

\section{Impact on the Group}

A $2 \times 2$ ANOVA on the impact item showed only a main effect for role, $F(1,88)=4.85, p<$ $.05, \eta^{2}=.05$, showing that leaders thought they could exert more influence on the group $(M=4.41, S D=1.34)$ than followers $(M=3.78, S D=1.38)$.

\section{Feelings of Entitlement}

A $2 \times 2$ ANOVA on the entitlement measure item revealed a main effect for role, $F(1$, $88)=17.30, p<.001, \eta^{2}=.16$. Leaders thought they had the privilege to earn more $(M=3.96, S D=1.76)$ relative to followers $(M=2.54, S D=1.55)$. However, an unexpected main effect for variance was also found (low variance: $M=3.61, S D=1.78$; high variance: $M=2.89, S D=1.75), \quad F(1$, $88)=4.46, p<.05, \eta^{2}=.05$. However, note that the effect size for variance was relatively weak and the effect size of role relatively strong. Moreover, the manipulation of variance had not been introduced yet, and as such we believe that the effect for variance can be attributed to chance.

\section{Harvesting Behavior}

To test for the effects of role and variance and the mediating role of entitlement on harvesting behavior, several regression analyses were performed (Baron \& Kenny, 1986). First of all, the effects of role and variance were regressed on the harvests in Trial 2 (as feedback about other members' harvests was only then known), thereby controlling for the effect of Trial 1 , showing an effect for Trial $1(\beta=.71, p<$ $.001)$, a main effect for role $(\beta=.16, p<.05)$, and an interaction effect between role and variance $(\beta=.15, p<.05$; see Figure 1$)$. A simple slope analysis demonstrated that there was an effect of role in the high-variance condition $(\beta=.31, p<.005)$, showing that leaders harvested more than followers. However, no effect in the low-variance condition was found between leaders and followers $(\beta=.02, p<.86)$. Then, to test whether leaders harvested more than followers in the high-variance condition because of feelings of entitlement (see De Cremer, 2003), the same regression analysis in the high-variance condition was performed (but this time we added entitlement as a covariate). This analysis showed that the effect of entitlement was significant $(\beta=.22, p<.01)$ and, more important, that the effect of role was reduced $(\beta=.20, p<.01)$. A Sobel test (Sobel, 1982) showed that this reduction was significant $(z=2.17, p<.05)$.

Moreover, additional analyses showed that followers' harvests in the high-variance condition were close to the optimal harvest (23 points), $t(19)=-1.64, p<.12$, whereas leaders' harvests deviated significantly from the optimal harvest, $t(21)=2.14, p<.05$.

\section{General Discussion}

The present research examined situations in which leaders harvest more from a common

\footnotetext{
${ }^{2}$ It is better to include the mediating variable before the dependent measure rather than after. It is indeed noted that "the very term 'mediator' (or 'intermediate variable') suggests that the mediator stands between that which it mediates and the outcome" (Kraemer, Stice, Kazdin, Offord, \& Kupfer, 2001, p. 850). We followed this suggestion to examine the potential mediating effect of the covariate entitlement. It is interesting to note that a previous study by De Cremer (2003) showed role effects similar to those we hypothesized when no questions with regard to possible mediating variables (such as entitlement) were asked.
} 


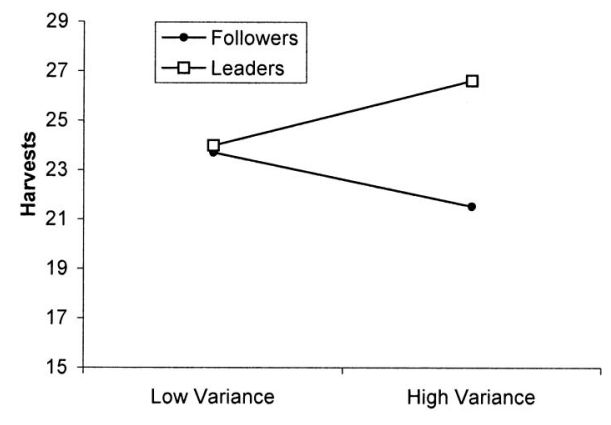

Figure 1. Harvesting behavior as a function of role and variance in harvesting.

resource than followers. In line with our predictions, we found that those occupying the role of leader harvested more than those occupying the role of follower, but only when harvesting behavior within the group was high in variability. Moreover, this effect could be explained at least partially by feelings of entitlement. In the following paragraphs we discuss the findings and their theoretical implications.

The most important finding was that harvesting behavior of leaders was a function of the variability in harvesting behavior within the group and feelings of entitlement. This is important because earlier resource dilemma studies (a) have advocated the appointment of a leader as an essential structural solution to maintain resources and (b) have shown that especially in situations where there is a lot of variation between group members' harvests, leaders were a preferred solution (Samuelson \& Messick, 1986; Samuelson et al., 1984). The present results (and very recent research; De Cremer, 2003; De Cremer \& van Dijk, 2005) show that leaders may not be such a successful solution, because they may harvest even more than followers. However, this negative leader behavior seems to emerge only when the situation does not reinforce a clear behavioral norm that group members are assumed to adopt, a norm that is particularly absent when there is high variability in the group's harvesting behavior (see Samuelson et al., 1986, for a similar line of reasoning about harvesting norms and variability). Hence, when a leader's influence is strongly needed (when there are unequal harvests among group members), leaders refrained from intervening; in contrast, they were more eager to harvest more from the common re- source. The present study is among the first to experimentally show that leaders may engage in more self-interested behavior than followers, and it is the first, to our knowledge, to point out when this is most likely to happen. Future research might focus on other situational variables that allow leeway for leaders to harvest more than followers.

An important reason that leaders engage in such self-interested action is that they feel more entitled to receive a larger share from the resource (see also De Cremer, 2003). Leader roles indeed include a belief that one is entitled to obtain more resources than those occupying a follower role (Fiske \& Taylor, 1991). Equity theory also suggests that leaders are entitled to more, because they will presumably have higher inputs and as such should receive higher outputs. This latter reasoning implies that leaders should be more aware of their influential role within the group, and our results supported this: Leaders believed they had more impact on the group. Taken together, it thus seems that leaders' feelings of entitlement go hand in hand with perceptions of having much impact on their followers. If this is the case, more self-interested behavior should emerge.

It is essential to note that leaders in the highvariance conditions deviated from the optimal harvest by harvesting more than the optimal harvest. This observation is in sheer contrast with prior research findings pointing out that leaders should be able to take care of a fair distribution of outcomes (see, e.g., Rutte \& Wilke, 1984) and, hence, should be a "model" for the other group members in order to set a norm for the group to follow. This idea of modeling has been recognized in the charismatic leadership literature, in which it is argued that, for example, leaders engaging in self-sacrificing acts (leading to high perceptions of charisma) can be seen as serving as a role model for cooperative behavior (see De Cremer \& van Knippenberg, 2002; Yorges, Weiss, \& Strickland, 1999). Therefore, leaders are often considered to exert influence when they lead by example, such as being fair and cooperative in social dilemmas. Does this mean, however, that followers will never consider it appropriate that leaders feel entitled to take more? In our view, followers might accept leaders to take more if they see the leader as someone who has done more than others, consequently reinforcing perceptions of justification (see also van Dijk \& 
Wilke, 1993). Thus, in general, leaders are seen as representative of fair and just behavior, but in keeping with this idea, if justified, leaders may take more than others (cf. equity theory; Adams, 1965).

Moreover, the optimal harvest can be considered a coordination rule that, if followed, ensures efficient use of the resource. Research by van Dijk and Wilke $(1996,2000)$ showed that people tacitly coordinate their decisions and in resource dilemmas are prone to follow an equality rule. Such coordination rules (like optimal harvest) can thus be perceived in terms of both fairness and efficiency, and the present results seem to indicate that leaders violate both of these principles. It should be noted that in previous research, participants occupying a leader or follower role were the first to take from the resource, a scenario that does not represent the traditional resource dilemma, in which participants harvest simultaneously. However, the present research showed that the role effect also emerged when group members make decisions at the same time.

To conclude, the fact that leaders violate these principles might have negative consequences for the collective. As a result, followers might want to leave the group or even take retributive actions on the leader (Fitness, 2000). Therefore, organizations should be aware of whether situations are present in which leaders might violate both fairness and efficiency principles. It is important to organize these situations in such a way that leaders will take responsibility and create circumstances to prevent the violation of these principles.

\section{References}

Adams, J. S. (1965). Inequity in social exchange. In L. Berkowitz (Ed.), Advances in experimental social psychology (Vol. 2, pp. 267-299). New York: Academic Press.

Baron, R. M., \& Kenny, D. A. (1986). The moderator-mediator variable distinction in social psychological research: Conceptual, strategic, and statistical considerations. Journal of Personality and Social Psychology, 51, 1173-1182.

Dawes, R. M. (1980). Social dilemmas. Annual Review of Psychology, 31, 169-193.

De Cremer, D. (2003). How self-conception may lead to inequality: Effects of hierarchical roles on the equality-rule in organizational resource-sharing tasks. Group and Organization Management, 28, 282-302.
De Cremer, D., \& van Dijk, E. (2005). When and why leaders put themselves first: Leader behaviour in resource allocations as a function of feeling entitled. European Journal of Social Psychology, 35, 553-563.

De Cremer, D., \& van Knippenberg, D. (2002). How do leaders promote cooperation? Journal of Applied Psychology, 87, 858-866.

Fiske, S. T., \& Taylor, S. E. (1991). Social cognition (2nd ed.). New York: McGraw-Hill.

Fitness, J. (2000). Anger in the workplace: An emotion script approach to anger episodes between workers and their superiors, co-workers and subordinates. Journal of Organizational Behavior, 21, $147-162$.

Hardin, G. (1968, December 13). The tragedy of the commons. Science, 162, 1243-1248.

Kerr, N. L., \& Kaufman-Gililand, C. M. (1994). Communication, commitment, and cooperation in social dilemmas. Journal of Personality and Social Psychology, 66, 513-529.

Komorita, S. S., \& Parks, C. D. (1994). Social dilemmas. Dubuque, IA: Brown \& Benchmark.

Kraemer, H. C., Stice, E., Kazdin, A., Offord, D., \& Kupfer, D. (2001). How do risk factors work together? Mediators, moderators, and independent, overlapping, and proxy risk factors. American Journal of Psychiatry, 158, 848-856.

Messick, D. M., Wilke, H., Brewer, M. B., Kramer, R. M., Zemke, P. E., \& Lui, L. (1983). Individual adaptations and structural change as solutions to social dilemmas. Journal of Personality and Social Psychology, 44, 294-309.

Rutte, C. G., \& Wilke, H. A. (1984). Social dilemmas and leadership. European Journal of Social Psychology, 14, 105-121.

Samuelson, C. D. (1993). A multiattribute evaluation approach to structural change in resource dilemmas. Organizational Behavior and Human Decision Processes, 55, 298-324.

Samuelson, C. D., \& Allison, S. T. (1994). Cognitive factors affecting the use of social decision heuristics in resource-sharing tasks. Organizational Behavior and Human Decision Processes, 58, 1-27.

Samuelson, C. D., \& Messick, D. M. (1986). Alternative structural solutions to resource dilemmas. Organizational Behavior and Human Decision Processes, 37, 139-155.

Samuelson, C. D., \& Messick, D. M. (1995). When do people want to change the rules for allocating shared resources? In D. A. Schroeder (Ed.), Social dilemmas: Perspectives on individuals and groups (pp. 143-162). Westport, CT: Praeger.

Samuelson, C. D., Messick, D. M., Rutte, C. G., \& Wilke, H. (1984). Individual and structural solutions to resource dilemmas in two cultures. Journal of Personality and Social Psychology, 47, 94104. 
Sobel, M. E. (1982). Asymptotic intervals for indirect effects in structural equations models. In S. Leinhart (Ed.), Sociological methodology (pp. 290312). San Francisco: Jossey-Bass.

van Dijk, E., \& Wilke, H. (1993). Differential interests, equity, and public good provision. Journal of Experimental Social Psychology, 29, 1-16.

van Dijk, E., \& Wilke, H. (1996). Tacit coordination and fairness judgments in social dilemmas. In W. B. G. Liebrand \& D. M. Messick (Eds.), Frontiers in social dilemma research (pp. 117-134). Berlin, Germany: Springer-Verlag. van Dijk, E., \& Wilke, H. (2000). Decision-induced focusing in social dilemmas: Give-some, keep-some, take-some, and leave-some dilemmas. Journal of Personality and Social Psychology, 78, 92-104.

Yorges, S. L., Weiss, H. M., \& Strickland, O. J. (1999). The effect of leader outcomes on influence, attributions, and perceptions of charisma. Journal of Applied Psychology, 84, 428-436.

Received November 3, 2004

Revision received April 8, 2005 Accepted April 8, 2005 